\title{
Esophageal variceal treatment using a novel Doppler probe method
}

Esophageal variceal recurrence after endoscopic treatment is a frequent event $[1-4]$. Some studies have reported that endoscopic treatment assisted by endoscopic ultrasonography (EUS) that can evaluate variceal size and hemodynamics is effective in preventing variceal recurrence $[3,4]$. Additionally, color Doppler evaluation by EUS is less invasive and enables endoscopists to identify the varices to be treated [4]. However, the DopplerEUS method has issues related to its use: it is time-consuming, it is complicated to use convex transducers, and it requires scope replacement for additional treatment. The latest method, Doppler probe ultrasonography, uses a through-thescope Doppler probe (Compumedics, DWL, Singen, Germany) (> Fig. 1 a) that can evaluate the direction, waveform (that helps distinguish between arteries and veins), and the amount of blood flow ( Fig. 1 b, c) [5]. Moreover, Doppler probe ultrasonography is simple, noninvasive, and requires no scope replacement for additional treatment. The procedure involves 1 ) identification of more risky varices, 2) detection of penetrating varices, 3) assisting appropriate hemostasis, and 4) evaluation after hemostatic treatment. Here we demonstrate two variceal treatments using this novel approach ( $\triangleright$ Video 1 ).

Case 1 involved a patient with a history of esophageal variceal rupture. Although he had undergone repeated endoscopic variceal ligations, recurrence of varices was observed ( $\mathbf{F i g} \mathbf{2} \mathbf{a}$ ). We evaluated high-risk varices using Doppler probe ultrasonography (\Fig.2b). Because varices previously treated with endoscopic variceal ligation had a penetrating vein and massive blood flow, we performed an additional ligation at the site of vein penetration ( $\mathbf{F i g} \cdot \mathbf{2 c}$ ). Varices were evaluated afterwards and the effectiveness of hemostasis was confirmed ( Fig. $2 \mathrm{~d}$ ).

Case 2 had a history of hemostasis for gastric variceal rupture ( $\triangleright$ Fig. 3 a). Sub-
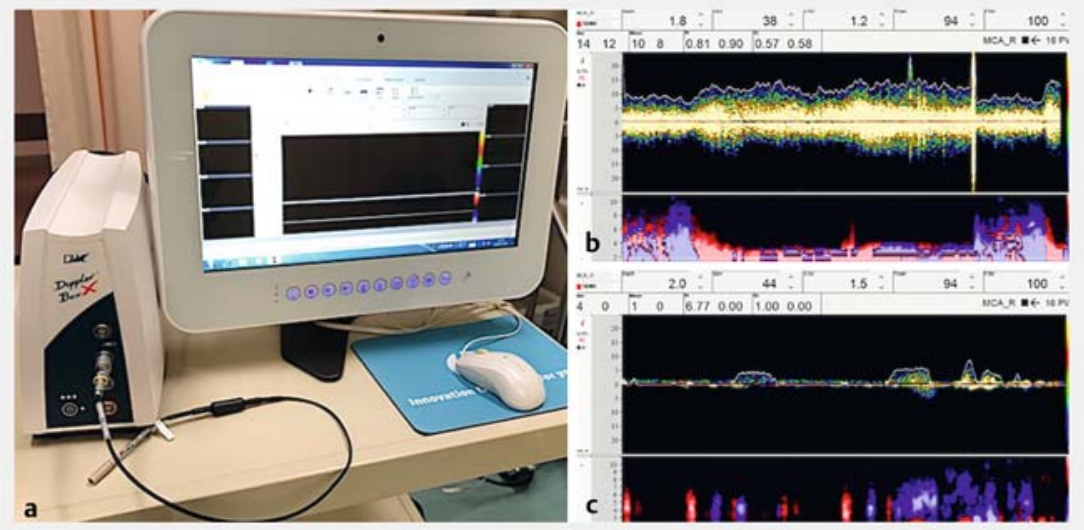

Fig. 1 a The image of the Doppler system with a reusable Doppler probe (diameter of $2 \mathrm{~mm}, 16 \mathrm{MHz}$ ). The Doppler system has audio and visual output signals. (Reproduced with permission from Compumedics.) b The visual graphic display reveals Doppler flow corresponding to the esophageal varix. c The Doppler flow disappeared after additional endoscopic variceal ligation.

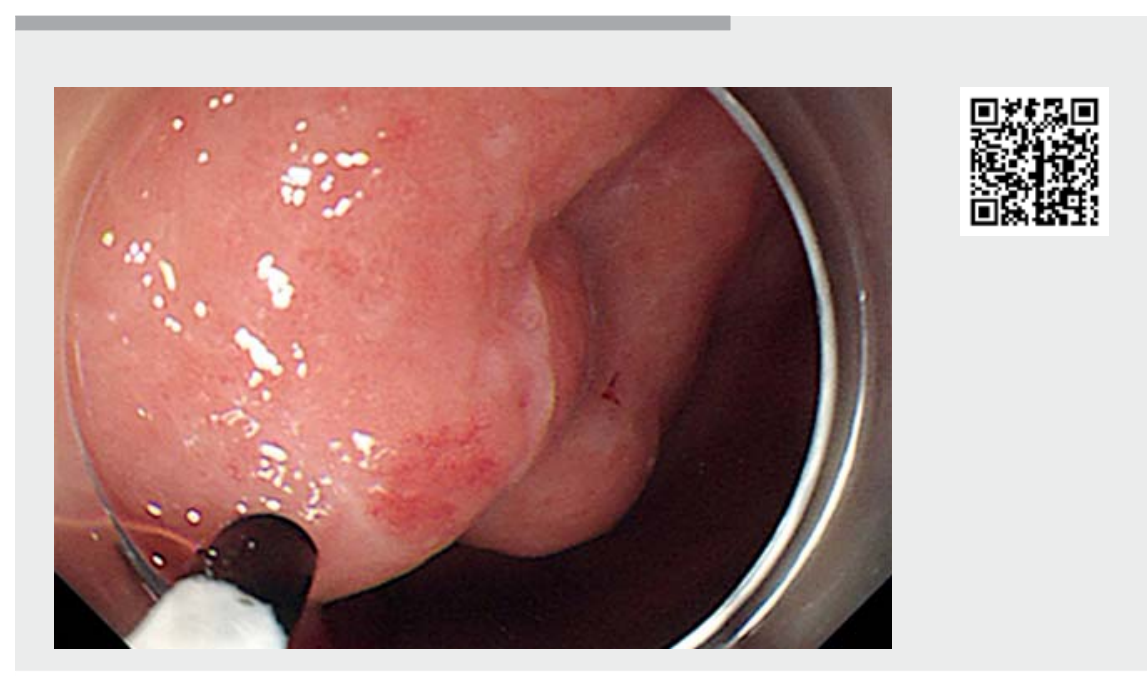

Video 1 Effective endoscopic hemostasis using the novel Doppler probe method.

sequently, esophageal varices developed. Esophageal varices continuous with the stomach were identified, and endoscopic variceal ligation was performed ( $\triangleright$ Fig. $\mathbf{3 b}$ ).

Both cases were treated effectively with endoscopic variceal ligation assisted by our novel Doppler probe ultrasonography.
Endoscopy_UCTN_Code_TTT_1AO_2AD

Competing interests

The authors declare that they have no conflict of interest. 


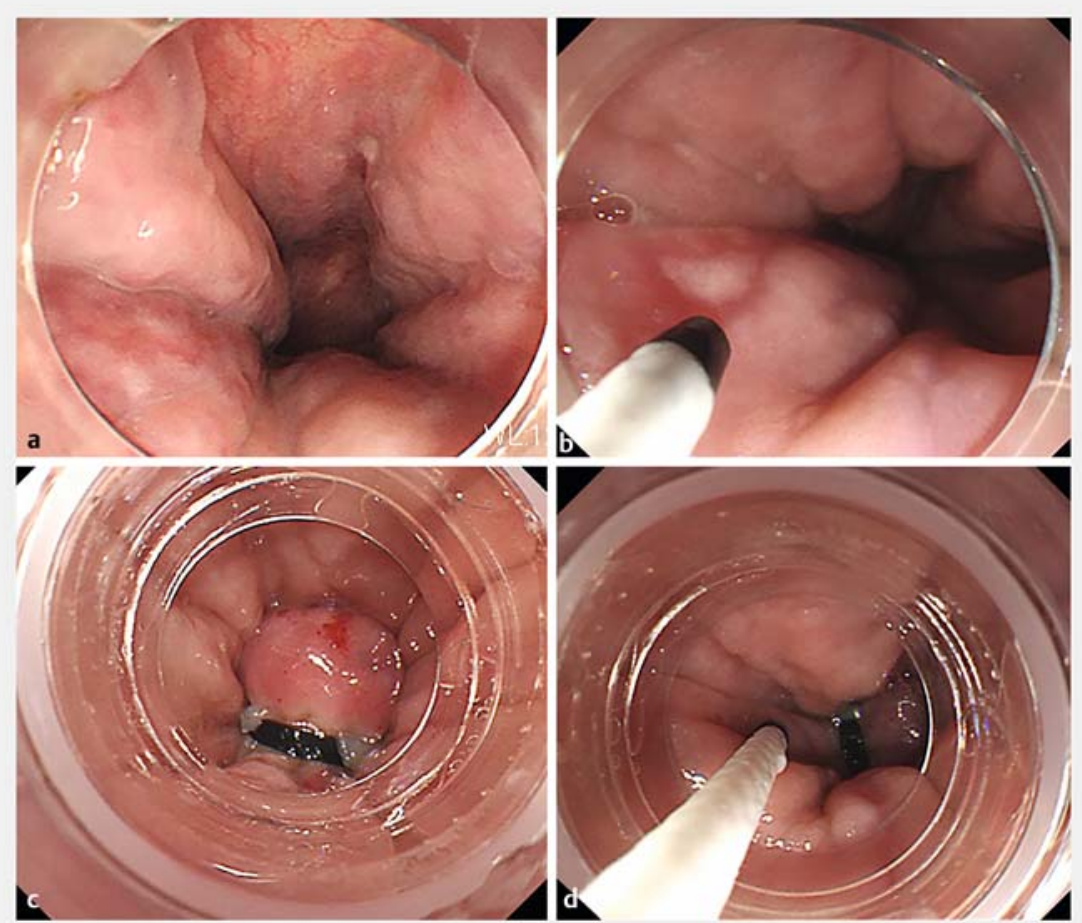

- Fig. 2 a Endoscopic view of the patient with esophageal variceal recurrence. b Evaluation of esophageal varices using the Doppler probe. The Doppler probe was maneuvered while observing the blood flow. c Additional band ligation was performed at a site where there was massive blood flow that we considered to have penetrating veins. $\mathbf{d}$ Confirmation by Doppler probe after band ligation was performed. If the blood flow had remained, additional variceal ligation would have been considered.
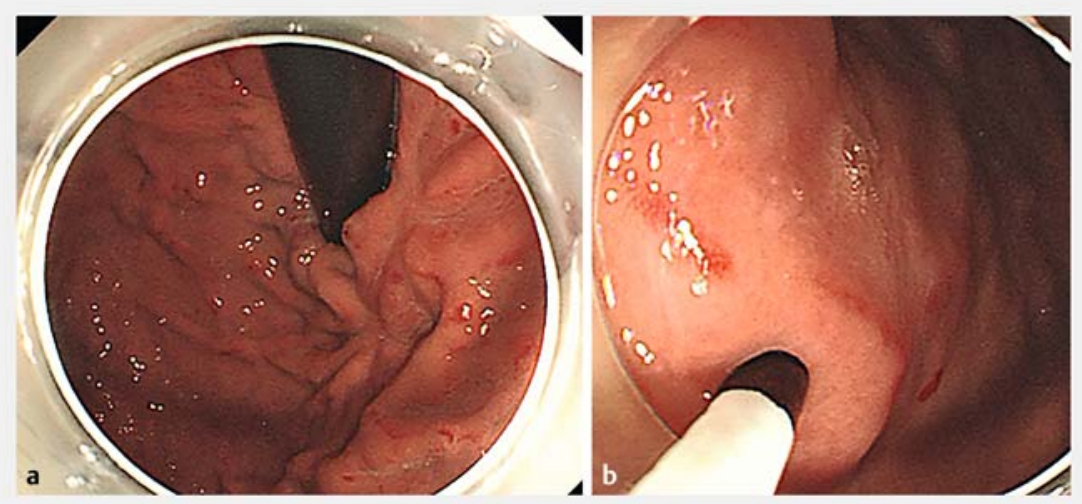

- Fig. 3 a Endoscopic view of gastric varices with scar formation due to previous variceal ligation. b Esophageal varices continuous with gastric varices were identified by the novel Doppler probe method; thereafter, esophageal varices were effectively treated by variceal ligation.

\section{References}

[1] Lv Y, Qi X, He C et al. Covered TIPS versus endoscopic band ligation plus propranolol for the prevention of variceal rebleeding in cirrhotic patients with portal vein thrombosis: a randomised controlled trial. Gut 2018; 67: $2156-2168$

[2] Mansour L, El-Kalla F, El-Bassat $\mathrm{H}$ et al. Randomized controlled trial of scleroligation versus band ligation alone for eradication of gastroesophageal varices. Gastrointest Endosc 2017; 86: 307-315

[3] Carneiro FO, Retes FA, Matuguma SE et al. Role of EUS evaluation after endoscopic eradication of esophageal varices with band ligation. Gastrointest Endosc 2016; 84: 400 407

[4] Hino S, Kakutani H, Ikeda K et al. Hemodynamic analysis of esophageal varices using color Doppler endoscopic ultrasonography to predict recurrence after endoscopic treatment. Endoscopy 2001; 33: 869-872

[5] Shiratori Y, Ikeya T, Oguri N et al. Endoscopic Doppler probe ultrasonography for detecting blood flow at post-endoscopic submucosal dissection ulcers of the stomach. Endosc Int Open 2020; 8: E1086-E1090

\section{Bibliography}

Endoscopy 2021; 53: E419-E420

DOI 10.1055/a-1324-2591

ISSN 0013-726X

published online 27.1.2021

(c) 2021. Thieme. All rights reserved.

Georg Thieme Verlag KG, Rüdigerstraße 14, 70469 Stuttgart, Germany

\section{ENDOSCOPY E-VIDEOS}

https://eref.thieme.de/e-videos

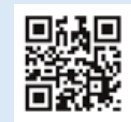

Endoscopy E-Videos is a free access online section, reporting on interesting cases and new techniques in gastroenterological endoscopy. All papers include a high quality video and all contributions are freely accessible online.

This section has its own submission website at

https://mc.manuscriptcentral.com/e-videos

\section{The authors}

\section{Yasutoshi Shiratori, Takaaki Yoshimoto, Kazuki Yamamoto}

Division of Gastroenterology, St. Luke's International Hospital, Tokyo, Japan
Corresponding author

\section{Yasutoshi Shiratori, MD}

9-1 Akashi-cho Chuo-ku, Tokyo 104-8340,

Japan

shiraya@luke.ac.jp 